\title{
How sharp is the tropopause at midlatitudes?
}

Thomas Birner, Andreas Dörnbrack, and Ulrich Schumann

Institut für Physik der Atmosphäre, DLR Oberpfaffenhofen, Wessling, Germany

Received 15 March 2002; revised 14 May 2002; accepted 21 May 2002; published 27 July 2002.

[1] Ten years of high-resolution radiosonde data are contrasted with fifteen years of ECMWF reanalysis (ERA) data to explore the tropopause region above two midlatitude stations (Munich and Stuttgart) in Southern Germany. We present time-averaged vertical profiles of several meteorological parameters relative to the tropopause. A strong mean inversion at the tropopause is evident from the radiosonde profiles with a vertical extension of about $2 \mathrm{~km}$ and a temperature increase of about $4 \mathrm{~K}$. The impact of the tropopause definition on the strength of this inversion is discussed as well as the relevance of baroclinic eddies in forming it. The climatological profiles for Munich and Stuttgart do not differ significantly. INDEX TERMS: 3362 Meteorology and Atmospheric Dynamics: Stratosphere/troposphere interactions; 3309 Meteorology and Atmospheric Dynamics: Climatology (1620); 3319 Meteorology and Atmospheric Dynamics: Genera circulation; 3329 Meteorology and Atmospheric Dynamics: Mesoscale meteorology; 3364 Meteorology and Atmospheric Dynamics: Synoptic-scale meteorology

\section{Introduction}

[2] During recent years there has been increasing interest in the dynamics and chemical transport in the tropopause (TP) region, i.e. the upper troposphere and lower stratosphere [Holton et al., 1995]. There are several definitions of the TP. The thermal TP is defined as the lowest level where the temperature lapse rate falls below $2 \mathrm{~K} \mathrm{~km}^{-1}$ and its average between this level and all higher levels within $2 \mathrm{~km}$ remains below this value [WMO, 1957]. Other TP definitions use specific thresholds of potential vorticity $(\mathrm{PV})$ and concentration of trace gases such as ozone [WMO, 1986; Bethan et al., 1996].

[3] In the climatological mean, the zonally averaged TP height decreases from the tropics towards the poles, e.g., [Hoinka, 1998]. The tropical troposphere and stratosphere are nearly convectively and radiatively adjusted, respectively. This generates the observed cold and sharp TP in the tropics [Highwood and Hoskins, 1998]. In the extratropics, radiative-convective equilibrium cannot be achieved because it is baroclinically unstable. Therefore, several idealized numerical studies investigate the contribution of baroclinic eddies in forming the extratropical TP, e.g., [Egger, 1995; Gabriel et al., 1999; Haynes et al., 2001]. The theory of baroclinic adjustment has been proposed to quantify this contribution [Stone, 1978; Held, 1982; Lindzen, 1993]. However, GCM simulations [Barry et al., 2000] reveal that the mean state of the extratropical troposphere is not baroclinically adjusted. Nevertheless, there is no doubt that baroclinic eddies control predominantly the TP in the extratropics.

[4] The climatological state of the TP was determined by meteorological analyses with a vertical resolution of about 1 $\mathrm{km}$ for the tropics [Highwood and Hoskins, 1998], the polar regions [Zängl and Hoinka, 2001] as well as globally [Hoinka, 1998]. Here, we use high-resolution radiosonde (RS) soundings to explore the TP-region above Southern Germany. Ten years of RS data are contrasted with ECMWF reanalysis (ERA) data for two locations. The much better vertical resolution of the RS data (up to $50 \mathrm{~m}$ ) reveals a much finer scale picture of the TP-region allowing a thorough quantification of the TP-sharpness. The role of baroclinic eddies forming the observed sharp mean TP is discussed.

\section{Data and Method}

[5] Ten years (1990-1999) of twice daily RS launches $\left(00,12\right.$ UT) from Munich (MUC, $\left.48^{\circ} \mathrm{N}, 12^{\circ} \mathrm{E}\right)$ and Stuttgart (STU, $49^{\circ} \mathrm{N}, 9^{\circ} \mathrm{E}$ ) are analysed for the fine-scale climatology. The data of the Väisälä, RS 80 soundings contain profiles of temperature $(T)$, relative humidity, ascent rate of the balloon, horizontal wind speed $(V)$, and wind direction $(\alpha)$. The accuracies amount to $0.2 \mathrm{~K}$ for $T, 2 \%$ for relative humidity, about $2.5 \mathrm{~ms}^{-1}$ for $V$, and about $5^{\circ}$ for $\alpha$. Wind speed and direction are obtained by radar tracking the ballon. Temperature and humidity have an average vertical resolution of $\approx 50 \mathrm{~m}$, wind speed and direction of $\approx 150 \mathrm{~m}$. The RS's reach maximum ceilings above $30 \mathrm{~km}$ in the considered region. Relative humidity values are biased at cold temperatures. Here, they are corrected by an empirical formula recently proposed [Miloshevich et al., 2001]. Mixing ratio (q) is computed with and without correction. However, reliable mean $q$ profiles can be obtained merely up to about TP level, where relative humidity values become less than their accuracy.

[6] To obtain a fine-scale climatology of the TP-region, we compute the thermal TP level $\left(z_{\mathrm{TP}}\right)$ for each radiosounding. The vertical profiles are interpolated by cubic splines to equally spaced (50 m and $150 \mathrm{~m}$, respectively, see above) levels relative to $z_{\text {TP }}$. Those profiles are then timeaveraged.

[7] Profiles of $T, V, \alpha$, and $q$ at two grid points nearby MUC and STU are extracted from the ERA-database for the years 1979-1993 (at 00, 06, 12, 18 UT). Their vertical resolution is $\approx 1 \mathrm{~km}$ in the TP-region. In contrast to the RSdata, the height of the dynamical TP is computed here using 3.5 PVU ( 1 PVU $=10^{-6} \mathrm{~K} \mathrm{~m}^{2} \mathrm{~kg}^{-1} \mathrm{~s}^{-1}$ ) as a threshold value. This is done in order to explore the dependence of the results on TP definition. Interpolation to $1 \mathrm{~km}$ spaced levels 

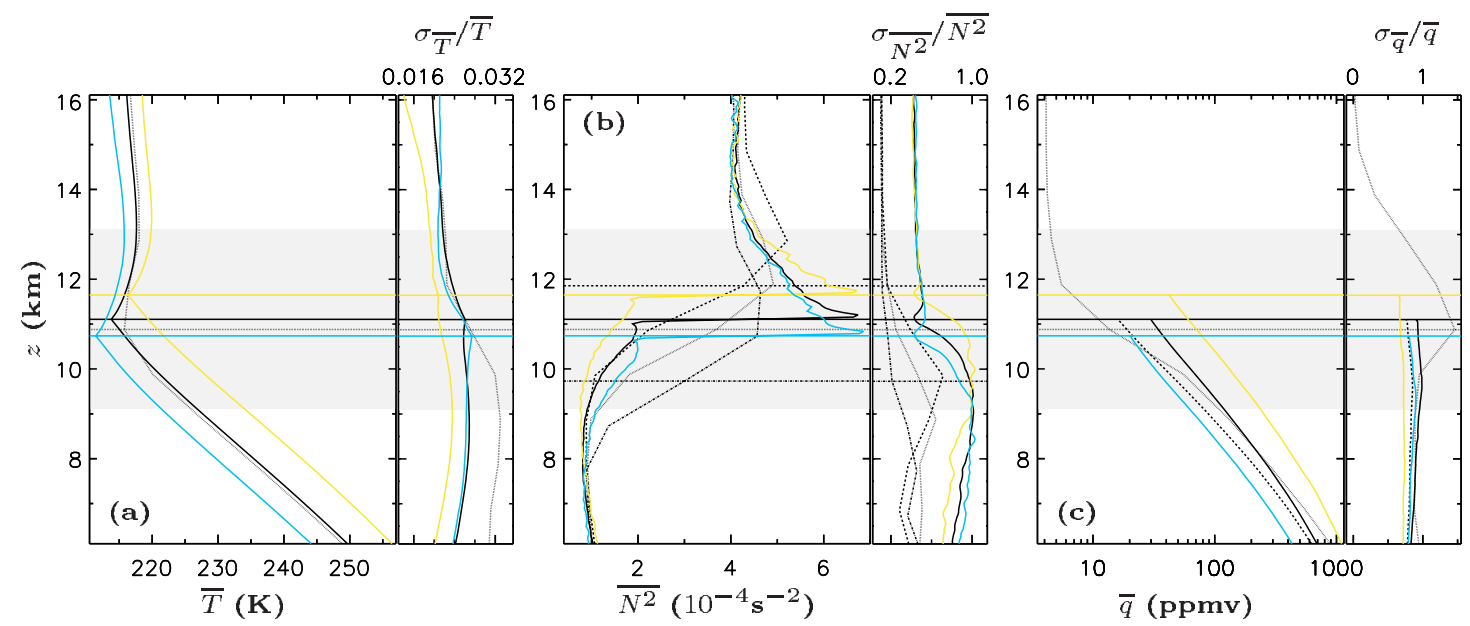

Figure 1. Mean profiles and corresponding relative standard deviations of (a) temperature, (b) buoyancy frequency squared, and (c) mixing ratio for Munich. Orange, blue, and black full lines represent averages for JJA, DJF, and all, respectively. Dotted lines denote mean ERA-profiles. Dash-dotted and dashed lines in (b) denote mean ERA-profiles for cyclonic and anticyclonic TP anomalies, respectively. The dashed line in (c) is the uncorrected mean profile. Profiles are time-averaged (denoted by the overbar) relative to the respective TP height (horizontal lines). The gray shading indicates the TP-region. Note the logarithmic abscissa in (c).

and time-averaging are done analogous to those of the RS profiles.

\section{Results}

[8] Figure 1 shows mean atmospheric profiles and corresponding relative standard deviations of the RS and ERA data for MUC. Mean profiles for STU are not plotted since they do not differ significantly. Selected mean values are summarized for both, MUC and STU in Table 1.

[9] The TP is marked by an inversion in the profiles of temperature. In summer (JJA), the TP level is higher and warmer than the overall average. The opposite is observed in winter (DJF). Independent of season, a sharp temperature inversion appears in the RS profiles. It has a maximum thickness of $\approx 2 \mathrm{~km}$ and a strength of $\approx 4 \mathrm{~K}$ (Figure 1a). It should be noted that about $85 \%$ of all profiles exhibit a TPinversion, i.e., $T\left(z_{\mathrm{TP}}+500 \mathrm{~m}\right)-T\left(z_{\mathrm{TP}}\right)>0$. The mean ERA and RS temperature profiles closely coincide. However, the ERA data underestimate the strength of the TP-inversion by a factor of $\approx 2$. This is certainly an effect of the much coarser vertical resolution. The small $(<1 \mathrm{~K})$ differences of $T$ between ERA and RS data might result from the different and longer time period of the ERA data. Moreover, the standard deviation of the ERA-profile is somewhat larger in the troposphere (Figure 1a).

[10] Outside the region $z_{\mathrm{TP}} \pm 2 \mathrm{~km}$ (which we call TPregion, shaded in Figures 1,2) the buoyancy frequency squared $N^{2}=(g / \Theta) \partial \Theta / \partial z(\Theta$ is the potential temperature $)$ stays almost constant (Figure 1b) as a consequence of the quasi-linear $T$-profiles. In contrast, inside the TP-region, $N^{2}$ jumps by a factor of almost four (three) at the TP level in the RS (ERA) data. Above $z_{\mathrm{TP}}$, a very stable layer with an extension of about $250 \mathrm{~m}$ and $N_{\max }^{2} \approx 7 \cdot 10^{-4} \mathrm{~s}^{-2}$ is evident exclusively in the RS profiles. The seasonal dependence is weak: smaller $N_{\max }^{2}$ occur in JJA, larger in DJF. Below $z_{\mathrm{TP}}$, the upper troposphere is less stable and the whole tropospheric $N^{2}$ fluctuates stronger (see standard deviations) for JJA than for DJF as expected from the stronger convective activity in JJA.

[11] The mixing ratio $q$ falls roughly exponentially with height. The corrected RS $q$-profile agrees better with the ERA profile than the uncorrected one. However, also the corrected RS profile differs significantly from the ERA one with a moister TP-region and a drier troposphere. As expected, the summer (winter) troposphere is moister

Table 1. Number of profiles (\#) and mean values of TP height $\left(\overline{z_{\mathrm{TP}}}, \mathrm{km}\right)$, TP temperature $\left(\overline{T_{\mathrm{TP}}}, \mathrm{K}\right)$, and wind direction $(\langle\bar{\alpha}\rangle$, degrees $)$ of RS and ERA data for both stations

\begin{tabular}{|c|c|c|c|c|c|c|c|c|}
\hline & \multicolumn{4}{|c|}{ Munich } & \multicolumn{4}{|c|}{ Stuttgart } \\
\hline & JJA & DJF & All & ERA & JJA & DJF & All & ERA \\
\hline \# & 1827 & 1789 & 7215 & 21916 & 1797 & 1665 & 6841 & 21916 \\
\hline$\overline{z_{T P}}$ & $11.65(1.11)$ & $10.73(1.36)$ & $11.11(1.33)$ & $10.88(1.52)$ & $11.64(1.10)$ & $10.80(1.35)$ & $11.15(1.32)$ & $10.84(1.56)$ \\
\hline$\frac{1}{T_{T P}}$ & $216.4(4.6)$ & $211.7(6.1)$ & $213.8(5.7)$ & $215.8(5.9)$ & $216.4(4.5)$ & $211.3(6.2)$ & $213.8(5.8)$ & $216.0(6.1)$ \\
\hline$\langle\bar{\alpha}\rangle$ & $274(22)$ & $302(22)$ & $285(22)$ & $285(22)$ & 274 (19) & $300(22)$ & $286(19)$ & $284(21)$ \\
\hline
\end{tabular}

Wind direction is averaged in time and in the range $z_{\mathrm{TP}} \pm 5 \mathrm{~km}$. RS averages are splitted into JJA, DJF, and all. Standard deviations are given in parentheses. Note the small differences between Munich and Stuttgart. 

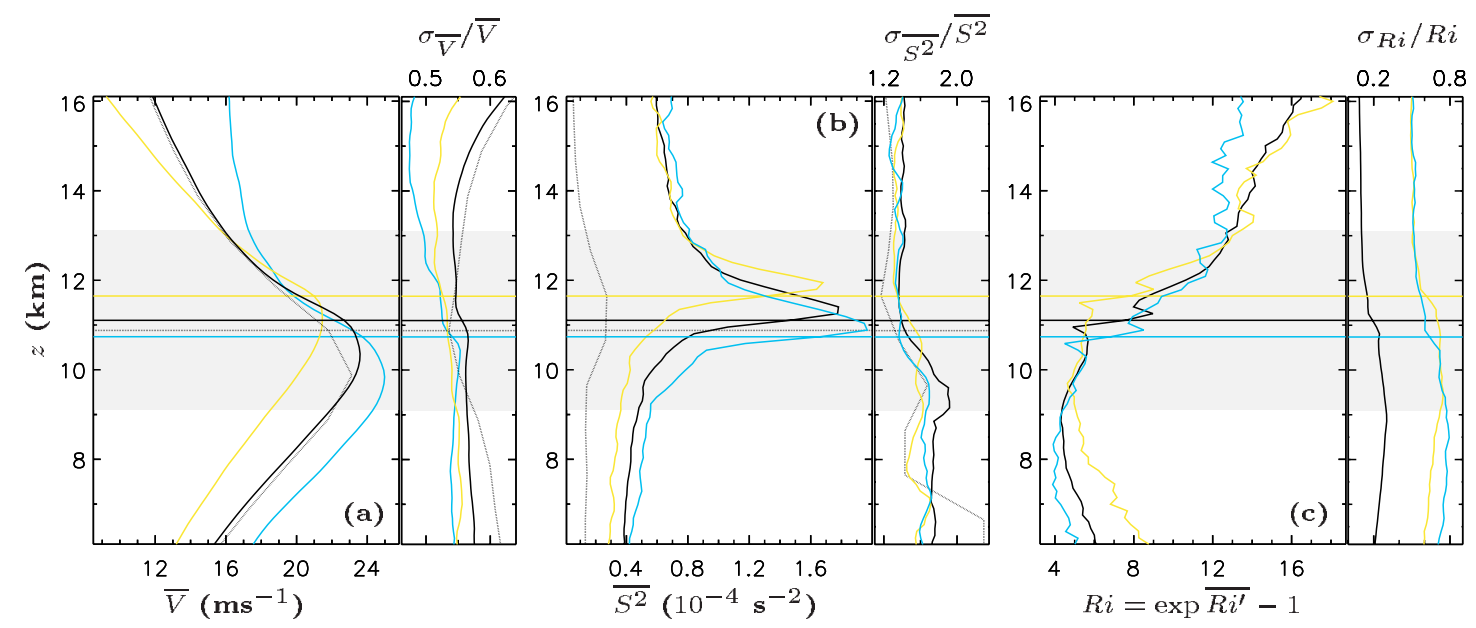

Figure 2. As Figure 1 but for (a) absolute wind speed, (b) vertical wind shear squared, and (c) Richardson number for Munich. Mean ERA-profiles are only shown in (a) and (b). For the $R i$-average see text.

(drier) than average. Stratospheric $q$ is adjusted to the climatological value $(\approx 4 \mathrm{ppmv})$ in the ERA data. The large standard deviations indicate the generally large variability of $q$.

[12] In Figure 2, mean profiles of $V$, vertical wind shear squared $\left(S^{2}=(\partial u / \partial z)^{2}+(\partial v / \partial z)^{2}, u\right.$ and $v$ are the zonal and meridional wind components), and Richardson number $\left(R i=N^{2} / S^{2}\right)$ are plotted for MUC. A pronounced jet is located slightly below the TP in all profiles. In DJF the jet is somewhat stronger than average. The jet in JJA is weaker and closer beneath $z_{\mathrm{TP}}$. Due to the summer easterlies in altitudes above $18 \mathrm{~km}, V$ decreases stronger into the stratosphere for JJA. The standard deviations are largest for the overall average indicating largest fluctuations in fall and spring. Since $\alpha$ is almost uniform with height in the TP-region (see Table 1 for values), profiles are not shown.

[13] The $S^{2}$-profiles (Figure 2b) obey a maximum directly above $z_{\mathrm{TP}}$ similar to $N^{2}$ (Figure 1b). A large $N^{2}$ denotes strong thermal stability whereas a large $S^{2}$ enforces dynamical instability. Evidently, $S^{2}$ above the TP is larger in DJF than the average and JJA value, respectively. Because of the large range of $R i$-values $\left(S^{2}\right.$ can be very small), a modified Richardson number $R i^{\prime}=\operatorname{sign}\left(\mathrm{N}^{2}\right) \ln \left(\left|N^{2}\right| / S^{2}+1\right)$ is first averaged and $R i$ is calculated using $R i=\exp \overline{R i^{\prime}}-1$. In contrast to the individual profiles of $N^{2}$ and $S^{2}, R i$ increases quasi-monotonically with height (Figure 2c). The shallow stable layer above the TP appears just as a weak local maximum because of the counteracting maxima in $N^{2}$ and $S^{2}$. Since the $S^{2}$ is smaller than its standard deviation (Figure $2 \mathrm{~b}$ ) and $S^{2}>0$, frequency distributions of $S^{2}$ are strongly asymmetric. The relatively small standard deviations of $R i$ result from the logarithmic average.

[14] Although the ERA wind speed profile is similar to the $\mathrm{RS}$ one, the wind shear differs remarkably. Obviously, the much higher vertical resolution of the RS data resolves the gradients much better. Despite of the $S^{2}$-increase inside the TP-region, $R i$ based on ERA data is always much larger than the maximum value in Figure 2c. Thus, the profile is not shown.

\section{Discussion and Conclusions}

[15] A comparison of the RS and ERA profiles reveals the following regarding the TP-region. Although mean TP height and temperature are obtained by different definitions, they coincide within a few percent $(\approx 2 \%$, see Table 1$)$. Also the mean profiles in the TP-region agree rather well. However, vertical gradients from the ERA data of temperature in the TP-region and wind speed differ remarkebly from those of the RS data. These differences certainly result from the much higher (factor 20) vertical resolution of the RS profiles. Therefore, the RS profiles indicate that the stably stratified layer above the TP level exhibits a larger inhibiting effect on troposphere-stratosphere exchange than usually calculated on the basis of coarsely resolved quantities by numerical models. Furthermore, the stable layer appearing above the dynamical TP indicates the qualitative independence of this conclusion on the TP definition. This is especially important as the dynamical TP is more relevant for tropospherestratosphere exchange studies, since PV is a materially conserved quantity under adiabatic motions. However, the operational RS network is too sparse, even in our region, to calculate reliable PV values. Thus, a high-resolution climatology relative to the dynamical TP can hardly be obtained. Nevertheless, it is possible to discuss the impact of the TP definition on the strength of the stable layer.

[16] The dynamical TP is defined by a specific value of $\mathrm{PV} \approx \rho^{-1}(\zeta+f) \partial \Theta / \partial z$ (here $3.5 \mathrm{PVU}$ ), where $\rho$ is density, $\zeta$ is the vertical component of relative vorticity, and $f$ is the Coriolis parameter. Thus, the dynamical TP captures changes in the dynamics (represented by $\zeta$ ) as well as changes in the thermal stratification (represented by $\partial \Theta / \partial z$ $\propto N^{2}$ ). An increase/decrease in $\zeta$ (due to cyclonic/anticyclonic amplification) at the dynamical TP must be balanced by a decrease/increase in $\partial \Theta / \partial z$ (i.e. also $N^{2}$ ) at this 
level in order to keep PV constant. On the other hand, the thermal TP only captures changes in the thermal stratification. Their lapse rate threshold (here $2 \mathrm{~K} / \mathrm{km}$ ) corresponds approximately to a specific value of $N^{2} \propto \partial \Theta / \partial z$. Thus, the dynamical TP generally lies below/above (smaller/larger $N^{2}$ ) the thermal TP for cyclonic/anticyclonic TP anomalies (cf. [Wirth, 2000]). Moreover, there exists a pronounced cyclone-anticyclone asymmetry leading to much larger and more frequent such TP height differences for cyclonic situations [Wirth, 2001]. The above described relations are illustrated in Figure $1 \mathrm{~b}$ for the ERA data. Mean profiles of $N^{2}$ are plotted for cyclonic $\left(\zeta_{\mathrm{TP}}>0.1 f\right)$ and anticyclonic $\left(\zeta_{\mathrm{TP}}<-0.1 f\right) \mathrm{TP}$ anomalies. Indeed, $N^{2}$ at the TP is smaller/ larger for cyclonic/anticyclonic anomalies. However, apart from the behaviour right at the TP, a maximum in $N^{2}$ is evident for both, cyclonic and anticyclonic cases. This emphasizes that the stable layer exists also above the dynamical TP.

[17] Indeed, the most striking and perhaps surprising feature of the RS climatology in Figure 1 is the thin, statically very stable layer just above the TP. Such a strong mean temperature increase cannot be found in meteorological analyses. It should be noted that averaging relative to the TP level was necessary to uncover this high lapse rate.

[18] What causes this strong mean TP-inversion?

[19] As noted earlier, synoptic-scale baroclinic eddies play a major role in forming the extratropical TP. Consider f.i. isentropic mixing by baroclinic eddies in the troposphere and subsidence in the stratosphere due to the stratospheric meridional circulation. The first process cools the upper troposphere. The second one warms the lower stratosphere. As a consequence an inversion forms at the top of the troposphere, i.e., at the TP. This is in close analogy to the formation of the inversion at the top of the convective boundary layer, e.g., [Tennekes, 1973]. However, an evaluation of the TP-inversion requires a quantification of the tropospheric mixing processes which is more complicated than in the case of the convective boundary layer and is beyond the scope of this paper. We remark, that Haynes et al. [2001] describe the stirring effect of baroclinic eddies in a forced-dissipative statistical equilibrium state of their spherical primitive-equation model. They find high stirring in the troposphere of the extratropics and a midlatitude transport barrier in the stratosphere (low stirring). This is in accord with our hypotheses above.

[20] There are further arguments in terms of baroclinic eddies supporting the existence of the TP-inversion. Gabriel et al. [1999] studied the effects of tropospheric and stratospheric eddies seperately in a $2 \mathrm{D}$ circulation model. In their study, the tropospheric eddies shift the TP at midlatitudes to higher altitudes compared to the noeddy case. However, an additional inclusion of the stratospheric eddies lowers the TP and leads to an inversion at the TP due to warming of the stratosphere. This can be readily seen in Figure 6 of Gabriel et al. [1999]. One should note, that their results are limited by the coarse vertical resolution of $\approx 2 \mathrm{~km}$ of their model.

[21] The above stated reasons are not intended to be complete. Rather they should stimulate further vertically high-resolution climatological analyses at other extratropical sites as well as idealized simulations to explain the observed sharp mean TP-inversion. The most striking points from this study are the strong mean TP-inversion and the climatological importance of vertical wind shear, both being only evident if the vertical resolution is high enough.

[22] Acknowledgments. We thank the DWD Oberschleissheim for the free availability of the RS data. We furthermore thank Jana Freund and Winfried Beer for their help in solving the difficulties with different data formats. Thanks to G. Zängl, J. Egger, and especially to K. P. Hoinka for their helpful discussions. The ERA data were provided by the latter within the latter within the ECMWF special project 'Climatology of the global tropopause'. Comments of V. Wirth on the manuscript were particularly helpful.

\section{References}

Barry, L., G. C. Craig, and J. Thuburn, A GCM investigation into the nature of baroclinic adjustment, J. Atmos. Sci., 57, 1141-1155, 2000.

Bethan, S., G. Vaughan, and S. J. Reid, A comparison of ozone and thermal tropopause heights and the impact of tropopause definition on quantifying the ozone content of the troposphere, Quart. J. Roy. Meteor. Soc., 122, 929-944, 1996.

Egger, J., Tropopause height in baroclinic channel flow, J. Atmos. Sci., 52, $2232-2241,1995$.

Gabriel, A., G. Schmitz, and R. Geprägs, The tropopause in a 2D circulation model, J. Atmos. Sci. 56, 4059-4068, 1999.

Haynes, P., J. Scinocca, and M. Greenslade, Formation and maintenance of the extratropical tropopause by baroclinic eddies, Geophys. Res. Lett., 28 , 4179-4182, 2001

Held, I. M., On the height of the tropopause and the static stability of the troposphere, J. Atmos. Sci., 39, 412-417, 1982.

Highwood, E. J., and B. J. Hoskins, The tropical tropopause, Quart, J. Roy. Meteor. Soc., 124, 1579-1604, 1998

Hoinka, K. P., Statistics of the global tropopause pressure, Mon. Wea. Rev, $126,3303-3325,1998$

Holton, J. R., P. H. Haynes, M. E. McIntyre, A. R. Douglass, R. B. Rood, and L. Pfister, Stratosphere-troposphere exchange, Rev. Geophys, 33, $403-439,1995$

Lindzen, R. S., Baroclinic neutrality and the tropopause, J. Atmos. Sci., 50, 1148-1151, 1993.

Miloshevich, L. M., H. Vömel, A. Paukkunen, A. J. Heymsfield, and S. J. Oltmans, Characterization and correction of relative humidity measurements from Vaisala RS80-A radiosondes at cold temperatures, J. Atmos. Oceanic Technol., 18, 135-156, 2001.

Stone, P. H., Baroclinic adjustment, J. Atmos Sci., 35, 561-571, 1978.

Tennekes, H., A model for the dynamics of the inversion above a convecTennekes, H., A model for the dynamics of the inversion a
tive boundary layer, J. Atmos. Sci., 30, 558-567, 1973 .

Wirth, V., Thermal versus dynamical tropopause in upper-tropospheric balanced flow anomalies, Quart. J. Roy. Meteor. Soc., 126, 299-317, 2000. Wirth, V., Cyclone-anticyclone asymmetry concerning the height of the thermal and the dynamical tropopause, J. Atmos. Sci., 58, 26-37, 2001. WMO, Meteorology-A three-dimensional science, WMO Bull., 6, (Oct), 134-138, 1957 .

134-138, 1957.
WMO, Atmospheric Ozone, WMO Report No. 16, 1986.

WMO, Atmospheric Ozone, WMO Report No. 16, 1986.
Zängl, G., and K. P. Hoinka, The tropopause in the polar regions, J. Climate, 14, 3117-3139, 2001.

T. Birner, A. Dörnbrack, and U. Schumann, Institut für Physik der Atmosphäre, DLR Oberpfaffenhofen, 82234 Wessling, Germany. (thomas. birner@dlr.de) 